\title{
CARTOGRAFÍA PARTICIPATIVA Y WEB 2.0: ESTUDIO DE INTERRELACIONES Y ANÁLISIS DE EXPERIENCIAS
}

María Purificación Subires-Mancera1: Universidad de Málaga. España purificacion@uma.es

\section{RESUMEN}

Cartografía participativa y web 2.0 beben de un mismo principio, el de que la ciudadanía, la comunidad, pueda tener voz, comunicarse, compartir, ofrecer su propia visión de la realidad. Las aplicaciones de mapas online, uno de los múltiples recursos de la web social, hacen posible que los usuarios puedan apropiarse del territorio, georreferenciando su propio espacio de acuerdo a sus intereses y necesidades. Los mapas online se convierten, de esta forma, en instrumentos para la participación ciudadana. En este artículo abordaremos la relación entre cartografía participativa y web 2.0 y ofreceremos el ejemplo de algunas de las experiencias de este tipo que se están llevando a cabo actualmente.

PALABRAS CLAVE: Internet, web 2.0, Cartografía Participativa, Aplicaciones de Mapas, Wikimapas

\footnotetext{
${ }^{1}$ Autor correspondiente

María Purificación Subires-Mancera: Departamento de Periodismo. Facultad de Ciencias de la Comunicación de la Universidad de Málaga (España)

Correo: purificacion@uma.es
} 


\title{
PARTICIPATORY MAPPING AND WEB 2.0: STUDY OF INTERRELATIONSHIPS AND ANALYSIS OF EXPERIENCES
}

\begin{abstract}
Both participatory mapping and web 2.0 feed from a same principle: citizens or community can have a voice, communicate, share, and give their own point of view. The online mapping applications, one of the many resources of the social web, enable users to take ownership of the territory, so they can georeference their own space, according to their interests and needs. The online maps are converted, therefore, in instruments for citizen participation. This article discusses the relationship between Web 2.0 and participatory mapping and offers some examples of this type of experiences that are currently carried out.
\end{abstract}

KEY WORDS: Internet, web 2.0, participative mapping, mapping applications, wikimaps

\section{INTRODUCCIÓN}

\subsection{Cartografía y cartografía participativa. Qué es la cartografía. Concepto de mapa}

La cartografía, cuyo origen se encuentra en la necesidad humana de ubicarse en el espacio en el que desarrolla su vida a través de su representación gráfica, puede definirse sencillamente como la ciencia, técnica y arte encargada de "la realización y el estudio de los mapas, en todos sus aspectos" (Robinson, Sale, Morrison \& Muehrcke, 1987, p. 3).

De ella debemos destacar su importancia en cualquier ámbito de actividad humana y en cualquier campo de conocimiento, puesto que su uso y aplicación práctica no sólo se limita al campo de la geografía y las ciencias, sino que se extiende a cualquier otra rama, como las humanidades, las ciencias sociales o la tecnología.

Los distintos autores estudiosos de la materia destacan especialmente el valor gráfico de dicha disciplina, por la capacidad para representar y exponer "ideas, formas y relaciones que tienen lugar en un espacio bi o tridimensional" (Robinson et al., 1987, p. 3) y aluden a la importancia que ha adquirido la cartografía desde hace unos años, motivada por la "progresiva toma de conciencia generalizada del valor estratégico del espacio" v la necesidad de "instrumentos útiles para el control u la planificación del 
Al hablar de documentos cartográficos, podemos distinguir entre mapas, cartas, planos, croquis y diagramas, fotografías aéreas e imágenes por satélite, y otro tipo de documentos como las perspectivas, vistas panorámicas, mapas en 3D (uno de los recursos que mayor desarrollo están teniendo hoy día) y maquetas (Jiménez \& Monteagudo, 2001, p. 118-120).

Uno de los principales tipos de documento cartográfico es el mapa, que puede definirse como una representación simplificada de toda o parte de la superficie de la Tierra (o de otro cuerpo celeste), en la que existe una relación dimensional de similitud que se basa en una escala (Jiménez y Monteagudo, 2001, p. 39), y que cuenta con dos elementos básicos: la localización y los atributos. Más allá de esta definición formal básica, el mapa puede ser entendido como un medio de comunicación espacial (Jiménez y Monteagudo, 2001, p. 4), de carácter gráfico, que destaca por su capacidad de hacer observables los fenómenos, y por su interés estratégico como herramienta de planificación del territorio.

El mundo de la cartografía ha ido evolucionando a lo largo de la historia de manera paralela a la sociedad, lo que ha hecho que con el desarrollo de las Tecnologías de la Información y la Comunicación, haya surgido, junto a la tradicional en formato papel, la cartografía digital y los Sistemas de Información Geográfica y más recientemente, las Infraestructuras de Datos Espaciales, que son accesibles online.

En este sentido, Internet se ha convertido en el elemento clave en el avance definitivo de la aplicación de la tecnología en el ámbito de la cartografía, al abrir la posibilidad de difundir toda la información geográfica a través de la Red. Antes, este tipo de información era de más difícil acceso, pero hoy día, gracias a Internet, y a la concienciación por parte de las propias instituciones de la necesidad de ponerla a disposición de todos, es posible acceder a una gran cantidad de recursos de interés. La irrupción de la web 2.0, que se basa en la participación activa de los propios usuarios, como creadores de contenidos, permite dar un paso más, al hacer posible que los ciudadanos puedan -a través de distintas aplicaciones web puestas a su disposición- elaborar sus propios mapas y compartirlos con el resto de navegantes.

\subsection{Cartografía participativa}

Un concepto que hermana con el de la filosofía de la web 2.0, aunque sea mucho anterior a ésta, es el de la cartografía participativa, que tiene su origen en los métodos de evaluación rural participativa, los cuales experimentaron un gran desarrollo durante la década de los ochenta y que tenían como punto de partida la inclusión de todos los integrantes de la comunidad en cualquier actividad relacionada con

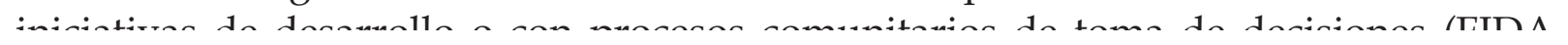


El Fondo Internacional de Desarrollo Agrícola (FIDA), que emplea la cartografía participativa en la ejecución de sus proyectos, concibe que ésta se basa en:

[...] la creación de mapas por comunidades locales, a menudo con la participación de organizaciones que les prestan apoyo, entre ellas autoridades públicas (de distintos niveles), ONG, universidades y otros agentes que se dedican al desarrollo y planificación relacionada con la tierra. ${ }^{2}$

La cartografía participativa aspira a dotar a los miembros de la comunidad las competencias y conocimientos necesarios para que sean capaces de elaborar sus propios mapas y representar su propio "saber espacial", tanto para su propio uso interno, como para transmitir este saber a otras personas ajenas a dicha comunidad. (FIDA, 2009, p. 4). A diferencia de la cartografía en su concepción tradicional:

Los mapas participativos constituyen a menudo una manera social o culturalmente distinta de entender el paisaje y contienen información que se excluye de los mapas habituales, los cuales representan normalmente los puntos de vista de los sectores dominantes de la sociedad. Los mapas de este tipo pueden plantear alternativas a los relatos e imágenes de las estructuras de poder existentes y convertirse en un medio de empoderamiento al permitir que las comunidades locales se representen espacialmente a sí mismas. ${ }^{3}$

Estos tipos de mapas "proporcionan una valiosa representación visual de lo que una comunidad considera que es su lugar y de sus características distintivas" (FIDA, 2009, p. 4), combinando características físicas, recursos disponibles y rasgos socioculturales. Incluso se considera que el empleo de este método de trabajo puede favorecer una mayor cohesión de la comunidad, incentivar el que sus miembros participen en la toma de decisiones sobre la tierra al tiempo que se produce una sensibilización sobre los más acuciantes problemas que la amenazan. Lo que lleva, finalmente a que este método pueda contribuir, como ya se ha mencionado antes, "al empoderamiento de las comunidades locales y de sus miembros" (FIDA, 2009, p. 4).

\footnotetext{
2 FIDA (2009): “Buenas prácticas en cartografía participativa. Análisis preparado para el Fondo
} 
Desde una visión similar, incidiendo en su poder transformador, Sabina Habegger autora de una Tesis Doctoral sobre Cartografía participativa- destaca:

La cartografía del territorio se propone como nuevo instrumento para la construcción de conocimiento desde la participación y el compromiso social, posibilitando una mirada inédita que hace visible lo invisible y posibilita la transformación de los territorios. ${ }^{4}$

Entre las aplicaciones de la cartografía participativa, la FIDA destaca, basándose en el caso de los países en desarrollo, las de "ayudar a las comunidades a articular y comunicar el conocimiento espacial a organismos externos", hacer posible que estas comunidades "registren y archiven los conocimientos locales", ayudarles a que puedan planear "el uso de la tierra y la gestión de los recursos", "sustentar los cambios que propugnan", "aumentar la capacidad" dentro de dichas comunidades o "resolver conflictos en torno a los recursos" (FIDA, 2009, p. 9-12).

Los instrumentos de los que puede hacer uso la cartografía participativa para ello son: el levantamiento de mapas artesanales, de mapas a escala e imágenes, de modelos tridimensionales, de Sistemas de Información Geográfica y de cartografía multimedia y en Internet (FIDA, 2009, p. 13-19). Del mismo modo que en el caso de la cartografía "tradicional" en este tipo de iniciativas de cartografía participativa también han comenzado a utilizarse las TIC, empleando por ejemplo, GPS, fotografías aéreas o imágenes de teledetección por medio de satélites (FIDA, 2009, p.5).

La cartografía participativa se ha convertido, en resumen, en un método en expansión, con el desarrollo de iniciativas tanto en países en desarrollo como desarrollados (FIDA, 2009, p. 4), que permite que los ciudadanos, que los miembros de una comunidad puedan apropiarse de su propio espacio en el sentido de poder cartografiarlo y ofrecer visiones alternativas a las oficiales, y que son más cercanas a sus propias necesidades e intereses.

\section{METODOLOGÍA}

La base metodológica se basa en el análisis de las anteriores escuelas de pensamiento que han tratado el tema que nos ocupa. Se trata de analizar los principales medios existentes hoy y aplicarles un método analítico textual que permita producir inferencias fenomenológicas o estructuras de pensamiento novedoso basado en este tipo de reflexiones que crean un puente entre las ideas anteriores (y sus realidades descritas) y las más modernas. 


\section{ANÁLISIS Y DICUSIÓN}

\subsection{Web 2.0 y participación ciudadana}

El desarrollo de la web 2.0 ha supuesto una auténtica revolución desde el punto de vista comunicativo al permitir a los usuarios - a través de aplicaciones gratuitas y de fácil manejo- una participación activa en la Red, ofreciéndoles la oportunidad de convertirse, a la vez que receptores, en productores y emisores de sus propios contenidos, rompiendo con la unidireccionalidad propia de los medios tradicionales y abriendo nuevos canales de comunicación horizontal, en los que es posible una verdadera retroalimentación o feed-back entre emisor y receptor. Gracias a las distintas aplicaciones de la llamada web 2.0 (blogs, plataformas para subir vídeos o fotografías, redes sociales, wikis, podcast, aplicaciones de mapas...) los usuarios consiguen tener voz, convertirse en portavoces de sus propias demandas y ofrecer versiones alternativas a los discursos dominantes.

En este nuevo contexto, el de la era digital, en el que las Tecnologías de la Comunicación y la Información están presentes en todos los ámbitos de nuestra vida, surgen conceptos como el de ciudadano digital, que autores como Robles definen como aquel individuo que "ejerce la totalidad o parte de sus derechos políticos o sociales a través de Internet de forma independiente o por medio de su pertenencia a una comunidad virtual" (Robles, 2009, p. 55).

La inclusión digital se convierte de esta forma en un elemento básico, y la lucha contra la fractura digital en un objetivo primordial. Puesto que, a pesar de la enorme importancia que ha adquirido Internet en estos últimos años, pervive la brecha entre países, regiones y sectores de la población, impidiendo el acceso en igualdad de condiciones en una sociedad en la que prima el uso de la tecnología. Las TIC han reportado grandes ventajas a la sociedad y han logrado acabar "virtualmente" con la barrera del tiempo y del espacio, pero los problemas básicos de subsistencia de una buena parte de la población mundial siguen sin resolverse ${ }^{5}$.

Debemos recordar además que esta brecha no es sólo económica, sino también generacional, entre personas de distintas edades. En este sentido, cuando Robles reflexiona sobre el concepto de ciudadano digital señala que son tres los requisitos básicos que éste debe cumplir: "acceso a Internet, habilidades digitales y percepción de la utilidad de las tecnologías" (Robles, 2009, p. 55). Para sacar un buen partido del uso de las tecnologías es necesario, por tanto, disponer de acceso a Internet, pero también contar con los conocimientos suficientes para saber utilizar los distintos recursos 
Junto con el concepto de ciudadano digital, se encuentra el de e-participación. Clecia Colombo señala a este respecto, al reflexionar acerca del uso de las TIC como herramientas al servicio de la democracia, que la participación ciudadana puede provenir de dos vías diferenciadas: por una parte, de los propios ciudadanos, organizados en movimientos sociales o redes ciudadanas para acciones puntuales o prolongadas en el tiempo, y por otra, de las administraciones públicas, incentivando acciones "para que la ciudadanía participe en la toma de decisiones públicas" (Colombo, 2007, p. 9-10). La autora encuentra tanto ventajas como inconvenientes al uso de Internet como medio para la participación ciudadana en el ámbito político, advirtiendo que, en una situación ideal que -pese a las potencialidades de Internet-, en el momento actual no sería posible (debido a factores como la brecha digital):

[...] la red podría suponer un canal de comunicación interactiva y multidireccional entre representados y representantes que aumentaría la capacidad de información y comunicación en ambos sentidos, aumentando la transparencia de la información pública y el posible control de los ciudadanos sobre el Gobierno y el Parlamento. ${ }^{6}$

Y aunque esto aún no sea posible, si que se ha podido comprobar -teniendo en cuenta el gran peso que las aplicaciones de la web 2.0 están teniendo entre los ciudadanos para organizarse y difundir sus reivindicaciones- que las TIC "aceleran los procesos de cambio en las concepciones y maneras de hacer de los individuos, agudizando el sentimiento de choque con la democracia representativa" (Colombo, 2007, p. 11). La posibilidad de expresarse libremente en el mundo virtual hace que los ciudadanos también quieran hacerlo de igual manera en el mundo real.

La ciudadanía, que reclamaba nuevos espacios para el debate público, ha encontrado en la Red el lugar más idóneo, puesto que le permite expresarse en libertad, sin ningún tipo de censura -salvo la que se autoimponga ella misma o el lugar en el que publique, de acuerdo con la legalidad y con la defensa de los derechos humanos-, difundir sus demandas a cualquier parte del mundo, debatir entre sí, organizarse y trabajar de manera colaborativa en un entorno virtual, sin limitaciones espaciotemporales. Vivimos en una nueva cultura digital en la que prima la inteligencia colectiva y la generación colaborativa del conocimiento frente a lo individual. El hecho de que sean los propios usuarios los que produzcan los contenidos puede plantear dudas acerca de su fiabilidad, pero tampoco debemos olvidar que nunca antes habían existido tantas posibilidades para contrastar y corregir esa información, que se construye a partir del conocimiento de todos. 


\subsection{Cartografía participativa en la era de la web 2.0}

Si en un primer momento la cartografía participativa usaba, como vimos, métodos tradicionales como soporte (mapas artesanales, hechos a mano, por ejemplo), hoy día, gracias a Internet, y al desarrollo de las aplicaciones de mapas, consigue tener un carácter global y un mayor nivel de repercusión social. Además, encontramos que la web 2.0 en sí comparte en su esencia los mismos principios de la cartografía participativa, puesto que ambas postulan la participación activa de los ciudadanos y el que puedan expresar y difundir sus propias ideas, intereses y demandas.

Si en un principio los mapas fueron en buena medida instrumentos al servicio del poder, hoy día se convierten en Internet en instrumentos democráticos, al alcance de todos los ciudadanos, en herramientas para la participación ciudadana y para el empoderamiento de las comunidades, tal como defiende la cartografía participativa.

Gracias a las aplicaciones de mapas disponibles a través de la Red, como por ejemplo los llamados wikimapas -que siguen la misma filosofía de trabajo colaborativo de los wikis, en cuya edición participan distintas personas-, los usuarios pueden cartografiar su propio espacio, crear comunidad en torno a un mapa, compartir información en relación a sus gustos, aficiones, lugares de interés, recursos culturales, demandas ciudadanas..., poner en valor cualquier parte del mundo, hacer que todo el espacio se vuelva visible y todo el mundo "salga en el mapa".

Contribuyendo de esta manera al empoderamiento ciudadano y comunitario, a través de la georreferenciación de su espacio por medio de estas aplicaciones de mapas online. Unas aplicaciones que además de convertirse en canales para la transmisión de ideas, proyectos y propuestas de mejora, cuentan con el valor añadido que les otorga el carácter multimedia de la Red (con la posibilidad de incluir texto, imagen, sonido, vídeo, animaciones...), enriqueciendo de esta manera el discurso.

Entre las distintas aplicaciones de mapas existentes hoy día en la Red -con cartografía gratuita, aunque no libre en todos los casos-, y con distinta curva de aprendizaje, según el caso, podemos destacar: Google Maps, Google Earth, Meipi, OpenStreetMap, IkiMap, Wikimapia, etc. De todas ellas, para llevar a cabo nuestro análisis práctico, y con el objeto de centrar nuestro estudio en un par de recursos concretos, hemos elegido iniciativas basadas en el empleo de las herramientas OpenStreetMap y Meipi. A continuación veremos algunos ejemplos prácticos de cartografía participativa que se basan en el empleo de alguna de estas dos herramientas. 


\subsection{Descripción de experiencias. Experiencias con OpenStreetMap}

Como se describe en su propio espacio web, OpenStreetMap "es una iniciativa cuyo objetivo es crear y proporcionar datos geográficos libres, tales como callejeros y mapas de carreteras, a todo el mundo"7. En el ámbito de España cuenta con su propia asociación, con sede en Madrid e inscrita en el registro de asociaciones desde el año 2009. Debido a su carácter libre, que lleva a que no utilice otros proveedores de mapas con información gratuita, pero no libre, OpenStreetMap trabaja en dos direcciones: por una parte, "permite a sus colaboradores crear y compartir datos geográficos abiertos y libres" y por otra, "presiona a instituciones y administraciones públicas para que liberen los suyos".

El que permita la edición colaborativa de los propios mapas, empleando GPS y otros recursos, hace que su curva de aprendizaje sea un poco más elevada que en otros casos. Cuando una zona del mapa aún no ha sido editada por ningún usuario y no se han aportado otros datos, aparece en blanco, sólo marcada por unas líneas básicas de carreteras, cursos de agua, topónimos, etc. La edición del mapa conlleva detrás un trabajo de trazado de calles y georreferenciado de espacios, que implica la necesidad de unos conocimientos previos del manejo de la herramienta por parte de los usuarios, como mencionábamos antes, al hablar de la mayor curva de aprendizaje para el uso de este recurso.

A continuación vamos a ver dos ejemplos del uso de OpenStreetMap:

Mapping Party Baeza ${ }^{8}$

Una "mapping party", concepto empleado habitualmente por OpenStreetMap, es "una concentración de voluntarios que quedan en un lugar para cartografiar de forma colectiva una ciudad o zona determinada"9. Es un buen ejemplo, por tanto, de cartografía participativa. En el caso de la Mapping Party Baeza, la iniciativa fue llevada a cabo en la localidad de Baeza, en la provincia de Jaén, por unos 100 voluntarios, con la ayuda de monitores y expertos -algunos de ellos integrantes del propio proyecto OpenStreetMap-. La experiencia se encontraba bajo el auspicio y la colaboración de diversas instituciones -como la Diputación de Jaén, el Instituto Geográfico Nacional, el Instituto Cartográfico de Andalucía, el Instituto de Estadística de Andalucía, la Universidad de Jaén o el Ayuntamiento de Baeza-, además de empresas y colectivos sociales. La Mapping Party se desarrolló durante un fin de semana de abril de 2011, y tras ella, la Universidad de Jaén se encargó de realizar un control de calidad de los datos publicados. Este hecho muestra el interés de la colaboración de expertos en este tipo de proyectos, con el fin de que la información publicada sea filtrada adecuadamente y no cuente con errores. 
En España se han llevado a cabo otras experiencias similares de mapping party bajo la iniciativa del proyecto OpenStreetMap en las ciudades de Soria y Zaragoza.

Wheelmap.org es una interesante y útil iniciativa, basada en OpenStreetMap, que consiste en un mapa de lugares accesibles en sillas de ruedas, en el que cualquier persona puede participar de manera voluntaria aportando información ${ }^{10}$.

Este mapa sirve de gran ayuda a las personas con limitaciones de movilidad que van en silla de ruedas, ya que les permite conocer si el lugar es "accesible" ("acceso liso, sin peldaños; todas las localidades tienen acceso y circulación para silla de ruedas (sin excepción); baños disponibles para personas con discapacidad"); "parcial" ("acceso no superior a $7 \mathrm{~cm}$; circulaciones accesibles a los recintos más importantes para usuarios en silla de ruedas"); "inaccesible" ("desnivel en acceso superior a $7 \mathrm{~cm}$ o escalera en la entrada, las localidades más importantes no tienen acceso para usuarios en silla de ruedas") o "desconocido" (sin información al respecto).

Consultando el mapa, los usuarios pueden saber, a través de una escala de colores basada en esos cuatro atributos (accesible, parcial, inaccesible o desconocido), si los semáforos, establecimientos o transportes públicos están o no adaptados. Para ello puede elegirse entre distintas categorías (alojamiento, comida, banco, compras, educación, deportes...)

El proyecto fue puesto en marchapor una asociación alemana llamada Sozialhelden ${ }^{11}$, y ya cuenta con versiones traducidas a diez idiomas, entre ellos el español ${ }^{12}$ (a cargo de Óscar Álvarez). Además de la consulta a la web, también se ha desarrollado una aplicación gratuita para IPhone.

La clave del éxito de esta iniciativa, como en cualquier otra de este tipo, en la que prima el trabajo voluntario colaborativo, está en la aportación de información por parte de los propios ciudadanos.

\subsection{Experiencias con Meipi}

Otro ejemplo de wikimapa lo tenemos en la iniciativa Meipi, para la creación de mapas temáticos. Como se explica en la propia web del proyecto:

Un meipi es un espacio colaborativo en el cual los usuarios pueden aportar información y contenido en torno a un mapa. Cada meipi tiene un contexto determinado, el cual puede ser local (con entradas localizadas en una zona geográfica determinada), o temático (cuando sus contenidos están relacionados 
A diferencia del ejemplo visto anteriormente, el de OpenStreetMap, en el que los usuarios se encargaban de crear los propios mapas, Meipi recurre a los mapas de Google como base, aunque entre sus retos está el de comenzar a utilizar recursos de dominio público, como el propio OpenStreetMap. ${ }^{14}$

Entre las características de Meipi, sus autores destacan la posibilidad de que los usuarios puedan subir archivos multimedia y asociarlos a un punto concreto del mapa, geolocalizándolos. Así, Meipi permite añadir imagen, texto, vídeo y sonido. Cuenta asimismo con un sistema de valoración de las informaciones publicadas, lo que -argumentan sus autores-, "garantiza la calidad de los contenidos y asegura la confianza de los participantes" (Sánchez, Di Siena, Álvaro y Álvaro, 2007, p. 2)

Los usuarios pueden participar en Meipi de tres maneras: creando su propio meipi, introduciendo nuevas entradas en otro meipi ya creado, o añadiendo comentarios a ese meipi. El único requisito para participar en él es el de estar registrado, pero el proceso para ello es bastante sencillo.

Cada meipi se organiza en cuatro apartados: mapa (en el que podemos ver el mapa a tamaño completo), lista (donde aparecen en orden todas las entradas publicadas), canales (cada uno de los cuatro bloques en los que el creador del meipi puede dividir los contenidos para organizarlos) y mosaico (una recopilación de las imágenes publicadas). Cada vez que un usuario quiere introducir una nueva entrada en un meipi lo único que tiene que hacer es aportar un título, una descripción, señalar el tipo de archivo (imagen, vídeo, audio o ninguno), indicar en cuál de los cuatro canales quiere que aparezca, la dirección postal (para poder georreferenciar ese punto -aunque también ofrece la posibilidad de introducir entradas sin localización-) y añadir etiquetas a esa entrada. Se trata por tanto de una herramienta bastante sencilla y con un funcionamiento muy similar al de los blogs.

Existen actualmente unos 1066 proyectos de Meipi, de 4301 usuarios y con 19009 entradas. Aunque debemos comentar que sólo una parte de ellos cuenta realmente con contenidos que se van ampliando, lo que muestra que existe interés por parte de algunos usuarios en crear uno de estos espacios, en torno a un tema o zona concreta, pero luego no se vuelcan contenidos. Aún así, son muchos e interesantes los ejemplos de proyectos que podemos encontrar y que cuentan con un nivel aceptable de participación, tanto con entradas introducidas por el propio creador del meipi, como de otros usuarios que se han sumado a la iniciativa añadiendo sus textos, vídeos, fotografías, etc. 
Otro aspecto que debemos resaltar en este tipo de experiencias es el desconocimiento acerca de la autoría -salvo que ésta se indique expresamente-, ya que los usuarios utilizan generalmente nicks o pseudónimos. Pero esto es algo lógico en la era de la web 2.0, en la que la autoría se diluye y todo forma parte de todos. Por otra parte, en muchos casos, se echa en falta una mayor información sobre los objetivos de ese meipi concreto, que impide que otros usuarios puedan conocer realmente con qué finalidad se está realizando.

Entre todos los ejemplos que podemos localizar en la web de Meipi, vamos a citar algunos casos que pueden constituir un buen ejemplo de wikimapa como herramienta de participación ciudadana. De esta forma, pueden convertirse en un espacio para la reivindicación, la lucha por el cumplimiento de derechos o la demanda de una política de ordenación del territorio en la que se tenga en cuenta la opinión de los ciudadanos:

a) Carreteras Reales ${ }^{15}$ : "[...] Nacionales con baches, carreteras de gran tráfico en la que apenas caben dos coches... Dilo aqui, alguien te escucha". (Centro del mapa: Madrid).

b) Fuentes potables de Madrid16: "Fuentes mapeadas por la Asociación de Viandantes A Pie. ¿Has visto alguna sin agua? ¿rota? ¿La han quitado? Mapea con nosotros pinchando en añadir entrada arriba a la derecha y sitúa tus fuentes". (Centro del mapa: Madrid)

c) BCNotrotour17: "Mapa con lugares donde se crean discrepancias entre los ciudadanos de Barcelona y la construcción urbanística". (Centro del mapa: Barcelona)

d) Cartografía crítica de As Pontes"18: "Cartografía crítica como parte del programa de reactivación de núcleos. Los usuarios podrán señalar puntos negros existentes en núcleos en vía de extinción". (Centro del mapa: As Pontes, España)

e) Observatorio Territorial y Ambiental Navarra19: "Cartografía ciudadana para el seguimiento de procesos territoriales. Sistema participativo de información social, ambiental y patrimonial de Navarra". (Centro del mapa: Pamplona, España)

f) Mapas y derechos 220: "Plataforma colaborativa por los derechos territoriales de los indígenas en La Argentina". (Centro del mapa: Argentina)

g) Crisis en los medios ${ }^{21}$ : "Las empresas editoriales españolas se apuntan a la crisis para reducir sus plantillas". (Centro del mapa: España)

\footnotetext{
15http://www.meipi.org/carreterasreales
} 
Los meipis también pueden servir a los usuarios para elaborar guías de recursos en torno a un tema de interés concreto, como catálogo de empresas, recorridos turísticos, lugares de ocio, etc.:

a) Participació a Castelló22: "Associacions i col•lectius a la ciutat de Castelló de la Plana."(Centro del mapa: Castelló de la Plana).

b) Sevilla está pa comérsela23: "Experiencias de producción y distribución alternativas de productos agroecológicos en Sevilla". (Centro del mapa: Sevilla)

c) Me voy de tapillas24: "Sitios de tapas, restaurantes, pubs y lugares para no perderse". (Centro del mapa: Granada)

También hay meipis para la salvaguardia de la memoria colectiva y del patrimonio, y para la realización de prácticas artísticas y culturales:

a) Memòries del comerç a Sant Fèlix 25: "Comerços que existeixen $i$ que han existit en el barri de Sant Fèlix (Girona)". (Centro del mapa: Girona, Cataluña)

b) Mapa Cultural del Uruguay26: "Este mapa pretende recoger la mayor cantidad posible de manifestaciones culturales del Uruguay". (Centro del mapa: Uruguay)

c) Laboratorio de imagen ${ }^{27}$ : "[...] experiencias de creación audiovisual en donde se explora a través de la imagen las prácticas urbanas en la ciudad de Bogotá [...]". (Centro del mapa: Bogotá, Colombia)

d) El sol se pone para todos 28: "Mapa donde situar los mejores atardeceres. Sube tus fotos y lugares favoritos". (Centro del mapa: Madrid, España)

Estos ejemplos son sólo algunos de los proyectos desarrollados en Meipi. Junto a estos usos podemos encontrar muchos otros (políticos, personales, educativos...) lo que constituye una muestra del interés que este tipo de recursos, como los wikimapas, pueden tener en cualquier campo o actividad.

\section{CONCLUSIONES}

A partir del análisis y reflexión acerca de la cartografía participativa, la web 2.0 y los ejemplos de OpenStreetMap y Meipi, podemos extraer, entre otras, las siguientes conclusiones:

\footnotetext{
$22 \mathrm{http}: / /$ www.meipi.org/participaciocastello

${ }^{23}$ http:// www.meipi.or/sevillapacomersela
} 
En primer lugar, hemos de destacar que los recursos de la web 2.0, gracias a las posibilidades que ofrecen a los usuarios para comunicarse, compartir información y participar de manera colectiva en la producción de contenidos -entre ellos, la elaboración de mapas- se convierten en un interesante instrumento al servicio de la cartografía participativa. A ello hemos de añadir el carácter global y el mayor nivel de repercusión y de implicación social de la información difundida. Y como valor clave debemos resaltar el carácter multimedia de Internet -la posibilidad de combinar información en distintos formatos (vídeo, texto, sonido, animación, imagen fija, panorámica $360^{\circ} \ldots$ ).

Gracias a las herramientas disponibles para producir y compartir contenidos, como los mapas, se generan unas dinámicas de participación en la comunidad, que contribuyen, a través de la llamada inteligencia colectiva, a la construcción colaborativa del conocimiento. Aunque la elaboración de contenidos por parte de usuarios no expertos puede generar incertidumbres acerca de su fiabilidad, debemos destacar la posibilidad de continua revisión y pulido de la información por parte de todos, y la participación de usuarios expertos, lo que entronca con los propios métodos e ideas de la cartografía participativa, donde las instituciones colaboradoras en los proyectos también ejercen ese papel de apoyo.

En general, debemos recordar el valor que los mapas tienen como instrumentos para la planificación del territorio, ya que trabajar sobre ellos nos ayuda a conocer y comprender mejor nuestro entorno e identificar deficiencias y aspectos necesitados de mejora. Un mapa nos permite catalogar y georreferenciar los recursos disponibles en una zona y establecer itinerarios y planes de trabajo en función de las necesidades detectadas. El hecho de que sean los propios ciudadanos los que puedan emplear este medio, en un entorno digital, para realizar sus propias contribuciones, demandas y reivindicaciones -y expresar su disconformidad respecto a decisiones políticas, por ejemplo-, hace de él un instrumento clave para la participación ciudadana en la sociedad digital.

Como hemos podido observar a través del análisis de las distintas experiencias mencionadas, mientras en unos casos se aprecia un propósito de reivindicación, con el planteamiento de propuestas desde una visión crítica o alternativa a los discursos dominantes, en otros se percibe una visión más cercana a la de servicio público, actuando simplemente como espacios recopilatorios de información de interés.

Los ciudadanos quieren tener voz, expresarse, decir lo que opinan, lo que explica el gran nivel de acogida que tiene aplicaciones como esta, en la que todos pueden participar, situando sobre el mapa aquello que le motiva, afecta o concierne, sea de 
Los movimientos alternativos, con escasa presencia en los medios, pueden hacer también visible su mensaje a través de esta vía. Además, estos mapas se convierten en punto de referencia para asociaciones y colectivos que trabajan en torno a un mismo tema de interés o área geográfica. Y también pueden servir de escenario para la plasmación de las propias vivencias personales, experiencias y espacios de interés comunes.

Pero además de todo ello, este tipo de iniciativas contribuyen a la puesta en valor del territorio, de los espacios naturales y culturales, de las propias localidades, y sirven para la toma de conciencia ciudadana y para el conocimiento de la propia evolución histórica de los territorios. De esta forma, se convierten en medios para la reflexión sobre el uso de los espacios públicos y en herramientas para la puesta en valor de las comunidades y de lo propio y para el empoderamiento ciudadano en la era digital.

\section{REFERENCIAS}

Colombo Villarrasa, C. (2007). e-Participación: Las TIC al servicio de la innovación democrática. Editorial UOC. Barcelona.

FAO (2011). El estado mundial de la agricultura y la alimentación. Recuperado el 20 de noviembre de 2011, de http:/ / www.fao.org/ docrep/013/i2050s/i2050s.pdf.

FIDA (2010). El enfoque adaptativo del FIDA relativo a la cartografía participativa. Diseño y ejecución de proyectos de cartografía participativa. Recuperado el 17 de noviembre de 2011, de http:/ / www.ifad.org/pub/map/pm_s.pdf.

FIDA (2009). Buenas prácticas en cartografía participativa. Análisis preparado para el Fondo Internacional de Desarrollo Agrícola (FIDA). Recuperado el 17 de noviembre de 2011, de http:/ / www.ifad.org/pub/map/pm_web_s.pdf.

Habegger Lardoeyt, S. A. (2008). La cartografía del territorio como práctica participativa de resistencia. Procesos en metodología implicativas, dispositivos visuales y mediación pedagógica para la transformación social. Málaga: Universidad de Málaga. Recuperado el 17 de noviembre de 2011, de http://www.biblioteca.uma.es/bbldoc/tesisuma/17678961.pdf.

Jimenez Pelayo, J. \& Monteagudo López-Menchero, J. (2001). La documentación cartográfica: Tratamiento, gestión y uso. Huelva: Universidad de Huelva.

Robles, J. M. (2009). Ciudadanía digital: Una introducción a un nuevo concepto de 
Robinson, A. H.; Sale, R. D.; Morrison, J. L. \& Muehrcke, P. C. (1987). Elementos de cartografía. Barcelona: Ediciones Omega.

Sánchez Uzábal, A.; Di Siena, D.; Álvaro Rey, G. \& Álvaro Rey, J. (2007). Meipi: Sinergia entre redes digitales y redes físicas en Inclusiva-net. Recuperado el 21 de noviembre de 2011, de http:/ / medialab- prado.es/mmedia/565.

Sanchi Asociación Opepstreetmap España (2011). Accesibilidad y OSM: silla de ruedas. Recuperado el 21 de noviembre de 2011, de http:/ /www.openstreetmap.es/2011/07/05/ silla-de-ruedas/.

Sevillano, S.; Torres, J. \& Tamayo, J. R. (2011). Mapping Party Baeza. Recuperado el 21 de noviembre de 2011, de http://blog-idee.blogspot.com/2011/04/mappingparty-baeza.html.

UNIA, CarTac \& Trayectos.org. (2010). Taller lo que los mapas no cuentan. Construcción de cartografías participativas a partir de wikimapas. Recuperado el 19 de noviembre de 2011, de http://ocw.unia.es/creacion-contenidos-digitales/loque-los-mapas-no- cuentan/dossiertallerpdf.

\section{María Purificación Subires-Mancera}

Licenciada y DEA en Periodismo por la Facultad de Ciencias de la Comunicación y Máster en Desarrollos Sociales de la Cultura Artística por la Facultad de Filosofía y Letras. Actualmente es Becaria de Personal Docente e Investigador (Junta de Andalucía) en el Departamento de Periodismo de la Facultad de Ciencias de la Comunicación de la Universidad de Málaga, donde realiza su Tesis Doctoral. 